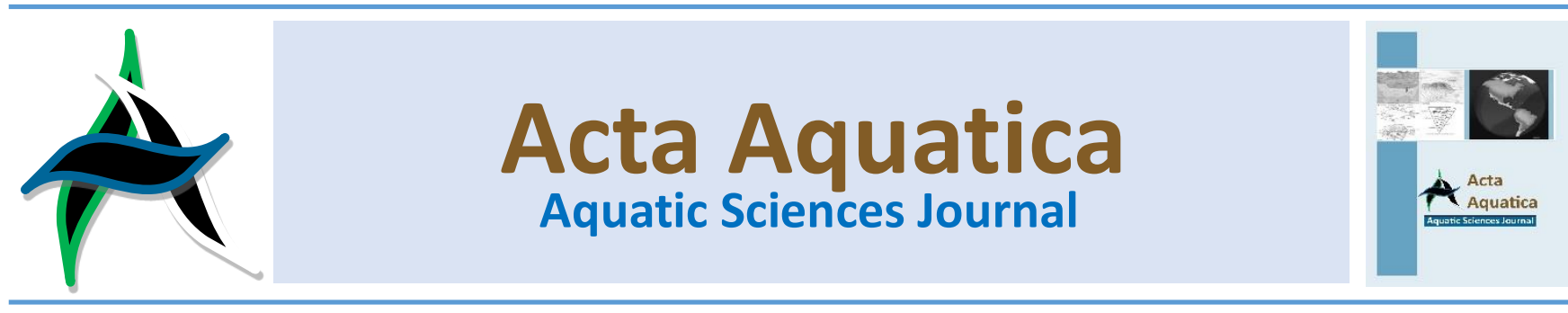

\title{
Pengaruh tanaman berbeda pada sistem akuaponik terhadap tingkat kelangsungan hidup dan pertumbuhan benih ikan lele (Clarias sp)
}

\section{The effect of different plants on aquaponics system on the survival rate and growth of catfish fingerling (Clarias sp)}

\author{
Suraiya Nazlia ${ }^{\text {a, } *}$ dan Zulfiadi ${ }^{\text {a }}$ \\ a Program Studi Pemanfaatan Sumberdaya Perairan, Fakultas Perikanan. Universitas Abulyatama. Aceh, Indonesia
}

\begin{abstract}
Abstrak
Penelitian ini bertujuan untuk mengetahui pengaruh tanaman berbeda pada sistem akuaponik terhadap kelangsungan hidup dan pertumbuhan benih ikan lele (Clarias sp). Penelitian ini menggunakan metode eksperimen dengan empat perlakuan dan tiga kali ulangan. Eksperimen yang digunakan dalam penelitian ini adalah Rancangan Acak Lengkap (RAL), menggunakan analysis of variance (ANOVA). Selanjutnya dilakukan uji lanjut menggunakan Uji Beda Nyata Terkecil (BNT). Hasil yang diperoleh menunjukkan bahwa adanya pengaruh nyata perlakuan pada kelangsungan hidup dan pertumbuhan bobot mutlak tetapi tidak berpengaruh pada pertumbuhan panjang mutlak benih ikan lele. Kelangsungan hidup tertinggi ditunjukkan pada perlakuan B (kangkung) sebesar $86.7 \%$ diikuti perlakuan C (kangkung dan sawi) sebesar $75.0 \%$ dan terendah pada perlakuan $C$ (sawi) sebesar $55.0 \%$. Sedangkan pertumbuhan bobot mutlak tertinggi pada perlakuan B (kangkung) dan C (kangkung dan sawi) dengan rata-rata sama dengan 1.97 gram, sedangkan perlakuan A (kontrol) dan D (sawi) secara dengan rata-rata pertumbuhan bobot mutlak sebesar 1.69 gram dan 1.54 gram secara berurutan.
\end{abstract}

Kata kunci: benih ikan lele sangkuriang; tanaman; sistem akuaponik; kelangsungan hidup; pertumbuhan

\begin{abstract}
This study aims to determine the effect of different plants on aquaponic system on the survival rate and growth of catfish seeds (Clarias $\mathrm{sp}$ ). The method used was experimental with four treatments and three replications. The experiment used was randomized design. Data were analyzed by using analysis of variance (ANOVA). The results showed that there were a significant effect of treatment on survival and absolute weight growth but did not affect the absolute length growth of catfish fingerling. The highest survival was shown in treatment B (water spinach) of $86.7 \%$ followed by $C$ (water spinach and mustard greens) treatment of $75.0 \%$ and the lowest in C treatment (mustard greens) amounted to $55.0 \%$. Additionally, the highest absolute weight growth were in treatment $B$ (water spinach) and $C$ (water spinach and mustard greens) with the same average to 1.97 gram, while treatment $A$ (control) and $D$ (mustard greens) were 1.69 gram and 1.54 grams respectively.
\end{abstract}

Keywords: sangkuriang catfish fingerling; plant; aquaponics system; survival; growth

\footnotetext{
* Korespondensi: Program Studi Pemanfaatan Sumberdaya Perairan, Fakultas Perikanan. Universitas Abulyatama. Jalan Blang BIntang Lama Km. 8,5 Lampoh Keudee, Aceh Besar. Provinsi Aceh, Indonesia. e-mail: suraiyanazlia_psp@abulyatama.ac.id doi: https://doi.org/10.29103/aa.v5i1.527
}

\section{Pendahuluan}

Ikan lele sangkuriang (Clarias sp) merupakan ikan air tawar yang cukup popular dan dibudidayakan hampir di seluruh wilayah Indonesia. Selain rasa yang enak dan gurih untuk dikonsumsi, Ikan komoditas unggulan ini memiliki beberapa kelebihan diantaranya teknik pemeliharaan yang sangat sederhana, masa panen yang cepat dan tahan terhadap kondisi lingkungan yang buruk. Kemudian nilai gizi yang terkandung pada ikan lele membuat ikan ini digemari oleh masyarakat sehingga memberikan prospek pasar yang baik.

Meningkatnya permintaan ikan lele harus terus didukung dengan produksi benih ikan yang tinggi. Hal tersebut tentu 
berdampak kepada sektor budidaya. Salah satu kendala yang harus dihadapi dalam kegiatan budidaya adalah kualitas dan kuantitas sumber daya air tawar yang semakin menurun seiring meningkatnya penggunaan air serta lahan untuk berbagai kepentingan. Pakan yang tidak habis dikonsumsi akan mengalami proses pengendapan. Pakan yang mengendap akan merusak kualitas air dan mempengaruhi pertumbuhan ikan oleh sebab itu perlu satu cara untuk mengatasi masalah tersebut. Salah satunya dengan menggunakan sistem akuaponik.

Sistem akuaponik merupakan kombinasi dari teknik pembesaran ikan atau akuakultur dengan teknik pembesaran tanaman secara hidroponik, Teknologi ini merupakan suatu sistem tanam terpadu yang menggunakan hasil perombakan bahan organik dalam budidaya ikan sebagai nutrisi bagi budidaya tanaman. Kelebihan sistem akuaponik adalah dapat memanfaatkan limbah organik budidaya ikan sebagai sumber nutrisi pada budidaya tanaman. Di samping itu, akuaponik juga memanfaatkan sistem budidaya tanaman untuk membersihkan dan memurnikan air untuk budidaya ikan.

Tanaman akuatik sangat cocok jika digunakan dalam sistem akuaponik dikarenakan tanaman akuatik memiliki kemampuan untuk menyerap nutrisi yang larut dalam air (Savidov, 2005). Terdapat beberapa jenis tanaman akuatik yang dapat dipakai dalam sistem akuaponik. Menurut Taufik (2010), tanaman kangkung dan sawi merupakan salah satu jenis tanaman yang dapat diaplikasikan dalam sistem akuaponik. Tanaman kangkung dan sawi dapat tumbuh baik pada sistem akuaponik.

Hal yang sama juga didukung dengan pernyataan Saptarini (2010), menyatakan bahwa tanaman kangkung darat dan sawi dapat tumbuh baik pada sistem akuaponik. erdasarkan hal tersebut, maka penulis tertarik untuk melakukan penelitian tentang pengaruh tanaman berbeda pada sistem akuaponik terhadap kelangsungan hidup dan pertumbuuhan benih ikan lele sangkuriang.

\section{Bahan dan metode}

\subsection{Waktu dan tempat}

Penelitian ini dilaksanakan pada bulan Januari - Maret 2017, di Laboratorium Terpadu Fakultas Perikanan Universitas Abulyatama.

\subsection{Bahan dan alat}

Bahan yang digunakan dalam penelitian ini adalah benih ikan lele sangkuriang, tanaman kangkung dan sawi, dan pakan berupa pelet. Peralatan yang digunakan adalah keranjang sebanyak 12 buah, wadah penelitian berupa bak beton sebanyak 12 buah ukuran $50 \times 100 \times 80 \mathrm{~cm}$, Styrofoam, termometer, pH meter, DO meter, penggaris, serok, dan timbangan digital.

\subsection{Metode penelitian}

Metode penelitian yang digunakan adalah metode eksperimental yaitu dengan mengamati pengaruh tanaman hidroponik dengan pemberian pakan 3 kali sehari untuk kelangsungan hidup dan pertumbuhan benih ikan lele sangkuriang. Rancangan penelitian yang digunakan adalah Rancangan Acak Lengkap (RAL) non faktorial dengan 4 perlakuan dan 3 ulangan (12 unit perlakuan). Adapun perlakuannya adalah sebagai berikut:
Perlakuan A : kontrol

Perlakuan B : kangkung

Perlakuan $C$ : kangkung dan sawi

Perlakuan D : sawi

\subsection{Prosedur penelitian}

\subsubsection{Persiapan wadah dan pemasangan akuaponik}

Penelitian diawali dengan persiapan wadah pemeliharaan yaitu bak beton. Wadah dibersihkan dan dicuci dengan desinfektan agar tidak terkontaminasi dengan organisme lain dan dikeringkan selama 1 hari sebelum penelitian. Kemudian pemasukan air dilakukan ke dalam kolam setinggi $30 \mathrm{~cm}$. setelah itu dilanjutkan dengan pemasangan akuaponik di dalam bak penelitian. Berikut merupakan desain sistem akuaponik yang dilakukan pada penelitian ini (Gambar 1).

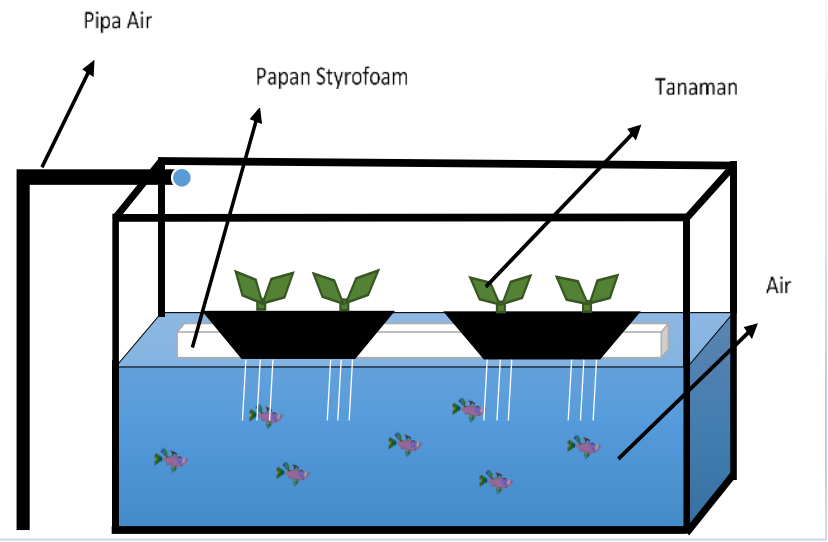

Gambar 1. Desain rangkaian alat akuaponik.

\subsubsection{Biota uji}

Biota uji yang digunakan adalah benih ikan lele sangkuriang dengan bobot \pm 0.35 gram dan ukuran panjang \pm 2.50 $\mathrm{cm}$. jumlah ikan per wadah adalah 20 ekor dengan jumlah total 240 ekor. Benih ikan lele tersebut diperoleh dari penjual benih ikan.

\subsubsection{Aklimatisasi}

Aklimatisasi ikan dimaksud untuk memberikan kesempatan pada ikan uji agar mampu menyesuaikan dengan kondisi penelitian. Aklimatisasi dilakukan selama 3 hari sebelum penelitian dimulai.

\subsubsection{Teknik pemberian pakan}

Pakan yang diberikan untuk benih ikan lele sangkuriang berupa pelet dengan persentase yang diberikan yaitu $4 \%$ dari pada berat individu. Frekuensi pemberian pakan sebanyak 3 kali sehari.

\subsubsection{Kualitas air}

Untuk pengelolaan kualitas air dilakukan pengukuran parameter kualitas air yang meliputi pengukuran suhu, DO, pH, dan amoniak. Pengamatan parameter kualitas air dilakukan beberapa kali dengan tujuan untuk mengetahui perubahan parameter fisika dan kimia selama pemeliharaan. 


\subsection{Parameter yang diamati}

\subsubsection{Sintasan atau tingkat kelangsungan hidup (survival rate)}

Sintasan atau tingkat kelangsungan hidup (SR) benih ikan lele dihitung dengan menggunakan rumus Effendie (1979) sebagai berikut:

$$
\mathrm{SR}=\mathrm{N}_{\mathrm{t}} / \mathrm{N}_{0} \times 100 \%
$$

Keterangan:

SR : Kelangsungan hidup benih (\%)

$\mathrm{N}_{\mathrm{t}} \quad$ : Jumlah ikan pada akhir penelitian (ekor)

$\mathrm{N}_{0} \quad$ : Jumlah ikan pada awal penelitian (ekor)

\subsubsection{Pertumbuhan}

Parameter yang diukur untuk mengetahui pertumbuhan benih ikan lele sangkuriang adalah pengukuran panjang dan bobot. Pengukuran yang diamati dilakukan dengan mengukur panjang dan bobot awal benih ikan, kemudian dilakukan pengukuran panjang dan bobot setiap minggunya serta pada akhir penelitian yaitu usia 42 hari.

\section{Pertumbuhan panjang mutlak:}

Pertumbuhan panjang mutlak ikan uji dihitung menggunkan rumus yang digunakan oleh Effendie (1979) sebagai berikut:

\section{Keterangan:}

$$
\mathrm{L}=\mathrm{Lt}-\mathrm{Lo}
$$

$$
\begin{array}{ll}
\mathrm{L} & \text { : Pertumbuahan panjang mutlak }(\mathrm{cm}) \\
\mathrm{Lt} & \text { : Panjang rata-rata individu pada akhir penelitian }(\mathrm{cm}) \\
\text { Lo } & \text { : Panjang rata-rata individu pada awal penelitian }(\mathrm{cm})
\end{array}
$$

Pertumbuhan bobot mutlak:

Perhitungan bobot mutlak dihitung dengan menggunakan rumus Effendie (1979) sebagai berikut:

$$
W=W t-W o
$$

Keterangan:

$$
\begin{aligned}
& \text { W : Pertumbuhan bobot mutlak (g/hari) } \\
& \text { Wt }: \text { Bobot ikan akhir pemeliharaan }(\mathrm{g}) \\
& \text { Wo }
\end{aligned}
$$

\subsection{Analisis data}

Model rancangan yang digunakan menurut Gomez dan Gomez (1995) adalah sebagai berikut:

Keterangan:

$$
Y i j=\mu+U i+K j+\Sigma i j
$$

Yij : Hasil pengamatan penelitian tanaman berbeda ke-K dan ulangan ke-i

$\mu \quad$ : Rataan umum

$\mathrm{U} \quad$ : Pengaruh ulangan ke i

$\mathrm{K} \quad$ : Pengamatan keberhasilan tanaman berbeda ke $\mathrm{j}$

I : : 1,2,3 (ulangan)

J : : 1,2,3 dan 4 (perlakuan)

$\Sigma i j \quad$ : Pengaruh galat perlakuan pada tanaman berbeda ke-K dan ulangan ke-i

Data hasil penelitian dianalisis dengan uji $F$, apabila terdapat perbedaan yang nyata $\left(F_{\text {hitung }}>F_{\text {tabel }}\right)$ maka akan dilakukan uji lanjut dengan menggunakan Uji Beda Nyata (BNT).

\section{Hasil dan pembahasan}

\subsection{Sintasan atau kelangsungan hidup (SR)}

Sintasan atau kelangsungan hidup adalah persentase jumlah ikan yang hidup pada akhir masa pemeliharaan dibandingkan dengan jumlah ikan pada saat awal penebaran. Hasil pengamatan dari penelitian yang dilakukan selama 42 hari terhadap sintasan atau kelangsungan hidup (SR) benih ikan lele dapat dilihat pada Gambar 2.

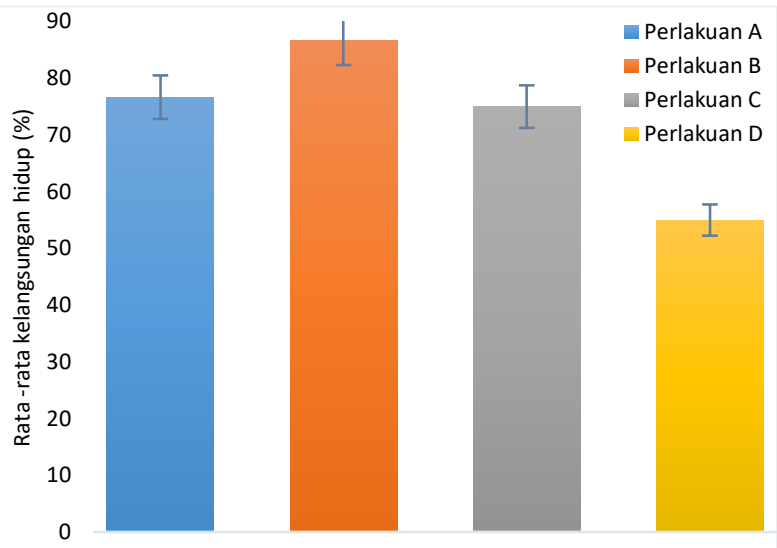

Gambar 2. Rata-rata tingkat kelangsungan hidup (\%) benih ikan lele sangkuriang.

Rata-rata tingkat kelangsungan hidup benih ikan lele sangkuriang tertinggi didapatkan pada perlakuan B (kangkung) yaitu sebesar $86.7 \%$, kemudian perlakuan A (Kontrol) yaitu sebesar $76.7 \%$ diikuti perlakuan C (kangkung dan sawi) sebesar $75.0 \%$, dan terendah pada perlakuan D (sawi) sebesar $55.0 \%$.

Hasil perhitungan analisis ragam menunjukkan bahwa sistem akuaponik dengan empat perlakuan memberikan pengaruh nyata terhadap kelangsungan hidup benih ikan lele sangkuriang $(P<0.05)$. Penggunaan tanaman $A$ (kontrol), $B$ (kangkung), C (kangkung dan sawi), maupun $D$ (sawi) pada sistem akuaponik menghasilkan nilai angka kelulushidupan yang berbeda secara statistik.

Menurut Siregar et al. (2009), tingkat kelangsungan hidup ikan dapat dipengaruhi oleh faktor dalam dan luar ikan. Faktor dalam terdiri dari umur dan kemampuan ikan dalam menyesuaikan diri dengan lingkungan. Faktor luar terdiri dari kondisi abiotik antara lain ketersediaan makanan dan kualitas media hidup. Menurut Rakocy et al. (1993) dalam Departemen Kelautan dan Perikanan (2008), tanaman akuatik secara efektif mampu memanfaatkan unsur hara sehingga memiliki beberapa keuntungan dari efisiensi penggunaan air dan pengurangan pencemaran limbah hasil buangan ke perairan umum. Ditambahkan pula oleh Saptarini (2010) dengan adanya akuaponik dalam sistem resirkulasi membuat kualitas air dapat dipertahankan dan memberi peluang untuk bakteri dapat tumbuh dan berkembang mengurai bahan-bahan organik dan anorganik yang berbahaya bagi kelangsungan hidup ikan. Dengan kata lain, menjaga kualitas media dengan sistem akuaponik dalam proses perbaikan kualitas air dapat berpengaruh terhadap kelangsungan hidup benih ikan lele.

\subsection{Pertumbuhan}

Pertumbuhan merupakan perubahan bentuk atau ukuran tubuh baik berat, panjang maupun volume dalam jangka waktu tertentu (Effendie, 1997). Menurut Rejeki (2001 dalam Teguh, 2008) tingkat pertumbuhan sangat bergantung pada spesies, lingkungan dan pakan. 


\subsubsection{Panjang mutlak}

Hasil pengamatan pertumbuhan panjang mutlak dapat dilihat pada Tabel 1. Dari data Tabel 1 dapat dilihat ada perbedaan nilai rata-rata antar perlakuan, jika dilihat pertumbuhan panjang tertinggi didapatkan pada perlakuan $C$ sebesar $10.86 \mathrm{~cm}$ (kangkung dan sawi), kemudian perlakuan $D$ sebesar $10.86 \mathrm{~cm}$ (sawi), diikuti dengan perlakuan A sebesar $10.14 \mathrm{~cm}$ (kontrol), dan terakhir pada perlakuan B sebesar 9.59 $\mathrm{cm}$ (kangkung).

Hasil perhitungan analisis ragam terhadap pertumbuhan panjang mutlak benih ikan lele sangkuriang menunjukkan tidak adanya perbedaan nyata antar perlakuan $(P>0.05)$. Hal ini menyatakan bahwa sistem akuaponik dengan empat perlakuan berbeda menggunakan tanaman A (kontrol), B (kangkung), C (kangkung dan sawi), dan $D$ (sawi) menghasilkan nilai pertumbuhan panjang mutlak yang tidak berbeda secara statistik. Dengan kata lain, tanaman akuatik pada sistem akuaponik tersebut tidak mempengaruhi pertumbuhan panjang mutlak benih ikan lele.

Tabel 1

Pertumbuhan panjang mutlak benih ikan lele sangkuriang.

\begin{tabular}{cccccc}
\hline Perlakuan & Ulangan & $\begin{array}{c}\text { Panjang } \\
\text { awal }\end{array}$ & $\begin{array}{c}\text { Panjang } \\
\text { akhir }\end{array}$ & $\begin{array}{c}\text { Pertambahan } \\
\text { panjang }\end{array}$ & Rata - rata \\
\hline \multirow{2}{*}{$\mathrm{A}$} & 1 & 2.50 & 12.29 & 9.79 & \\
& 2 & 2.50 & 12.80 & 10.30 & 10.1400 \\
& 3 & 2.50 & 12.83 & 10.33 & \\
\hline \multirow{2}{*}{$\mathrm{B}$} & 1 & 2.50 & 12.83 & 10.33 & \\
& 2 & 2.50 & 11.90 & 9.40 & 9.5867 \\
& 3 & 2.50 & 11.53 & 9.03 & \\
\hline \multirow{2}{*}{$\mathrm{C}$} & 1 & 2.50 & 13.61 & 11.11 & \multirow{2}{*}{10.8600} \\
& 2 & 2.50 & 13.57 & 11.07 & \\
\hline \multirow{2}{*}{$\mathrm{D}$} & 3 & 2.50 & 12.90 & 10.40 & \\
& 1 & 2.50 & 13.16 & 10.66 & \\
& 2 & 2.50 & 13.00 & 10.50 & 10.5400 \\
& 3 & 2.50 & 12.96 & 10.46 & \\
\hline
\end{tabular}

\subsubsection{Bobot mutlak}

Hasil pengamatan pertumbuhan bobot mutlak benih ikan lele sangkuriang tersaji pada Tabel 2.

Tabel 2

Pertumbuhan bobot mutlak benih ikan lele sangkuriang.

\begin{tabular}{cccccc}
\hline Perlakuan & Ulangan & $\begin{array}{l}\text { Bobot } \\
\text { awal }\end{array}$ & $\begin{array}{l}\text { Bobot } \\
\text { akhir }\end{array}$ & $\begin{array}{l}\text { Pertambahan } \\
\text { bobot }\end{array}$ & Rata - rata \\
\hline \multirow{2}{*}{$\mathrm{A}$} & 1 & 0.35 & 2.02 & 1.67 & \\
& 2 & 0.35 & 2.07 & 1.72 & 1.6933 \\
& 3 & 0.35 & 2.04 & 1.69 & \\
\hline \multirow{2}{*}{$\mathrm{B}$} & 1 & 0.35 & 2.30 & 1.95 & \\
& 2 & 0.35 & 2.35 & 2.00 & 1.9700 \\
& 3 & 0.35 & 2.31 & 1.96 & \\
\hline \multirow{2}{*}{$\mathrm{C}$} & 1 & 0.35 & 2.36 & 2.01 & \\
& 2 & 0.35 & 2.32 & 1.97 & 1.9700 \\
& 3 & 0.35 & 2.28 & 1.93 & \\
\hline & 1 & 0.35 & 1.90 & 1.55 & 1.5433 \\
& 2 & 0.35 & 1.87 & 1.52 & \\
\hline
\end{tabular}

Dari tabel dapat dilihat jika antara perlakuan B (kangkung) dan $C$ (kangkung dan sawi) memiliki nilai rata-rata yang sama yaitu sebesar 1.97 gram, sedangkan perlakuan $A$ (kontrol) dan D (sawi) secara berurutan memiliki nilai rata-rata pertumbuhan bobot mutlak yang lebih rendah sebesar 1.69 gram dan 1.54 gram.
Hasil perhitungan analisis ragam terhadap pertumbuhan bobot mutlak benih ikan lele sangkuriang menunjukkan adanya perbedaan nyata antar perlakuan $(P<0.05)$. Sistem akuaponik dengan menggunakan tanaman A (kontrol), B (kangkung), C (kangkung dan sawi), dan $\mathrm{D}$ (sawi) menghasilkan nilai rata-rata pertumbuhan bobot mutlak yang berbeda secara statistik. Dengan kata lain, perbedaan perlakuan tanaman pada sistem akuaponik memberikan pengaruh terhadap pertumbuhan bobot mutlak benih ikan lele.

\subsection{Kualitas air}

Kualitas air merupakan salah satu bagian terpenting dalam pengelolaan budidaya. Suplai air yang memadai akan memecahkan masalah dalam kegiatan budidaya ikan secara intensif. Hasil pengukuran parameter kualitas air selama penelitian dapat dilihat pada Tabel 3.

Tabel 3

Hasi pengukuran kualitas air selama penelitian.

\begin{tabular}{lcccc}
\hline \multicolumn{1}{c}{ Parameter } & A & B & C & D \\
\hline Suhu $\left({ }^{\circ} \mathrm{C}\right)$ & $26-27$ & $26-27$ & $26-27$ & $26-27$ \\
pH & $7-7,3$ & $7-7,8$ & $7-7$ & $7-7$ \\
DO $(\mathrm{ppm})$ & $5,5-6,11$ & $5,3-6,17$ & $5,13-6,14$ & $5,3-6,17$ \\
Amoniak $(\mathrm{mg} / \mathrm{L})$ & $0,30-$ & $0,194-$ & $0,119-$ & $0,273-$ \\
& 1,968 & 2,101 & 1,999 & 1,700 \\
\hline
\end{tabular}

Hasil pengukuran awal dan akhir terhadap parameter kualitas air media pemeliharaan dari setiap perlakuan menunjukkan masih dalam kisaran yang dianjurkan atau dalam kondisi layak untuk dijadikan media budidaya benih ikan lele sangkuriang. Berdasarakan tabel pengukuran kualitas air diperoleh bahwa suhu selama penelitian relatif stabil yaitu pada kisaran $26-27^{\circ} \mathrm{C}$. Hal ini sesuai dengan penelitian Yunus et al. (2014), suhu $26-28^{\circ} \mathrm{C}$ baik untuk pertumbuhan benih ikan lele sangkuriang. Selanjutnya Sunarman (2004) menyatakan bahwa kisaran suhu optimal untuk pertumbuhan ikan lele sangkuriang adalah $22-34^{\circ} \mathrm{C}$.

Kemudian selama penelitian tercatat nilai $\mathrm{pH}$ berkisar antara 7 - 7.8. Nilai tersebut merupakan nilai baik untuk kehidupan benih ikan lele sangkuriang yang sesuai standar Nasional Indonesia (SNI, 2000 dalam Yunus et al., 2014) yaitu antara 6.5 - 8.6. Kadar oksigen terlarut (DO) berkisar antara 5.3 - 6.11 ppm sangat baik untuk perkembangan benih ikan. Boyd dan Lichtkoppler (1991) menyatakan kandungan oksigen terlarut yang baik untuk ikan lele adalah lebih dari 5 ppm sementara Sunarman (2004) menyebutkan oksigen terlarut yang baik untuk pertumbuhan benih ikan lele sangkuriang adalah diatas dari 1 $\mathrm{mg} / \mathrm{L}$.

Selanjutnya kadar amoniak $\left(\mathrm{NH}_{3}\right)$ selama kegiatan penelitian tercatat sebesar $0.119-2.101 \mathrm{mg} / \mathrm{L}$. Menurut Robinette (1976) dalam Khodijah et al. (2015) kadar kelayakan amoniak $\left(\mathrm{NH}_{3}\right)$ dalam pemeliharaan benih ikan lele adalah $<1$ $\mathrm{mg} / \mathrm{L}$. Menurut Setijaningsih (2009), fungsi penggunaan tanaman pada sistem akuaponik ialah mengurangi limbah buangan hasil kegiatan budidaya melalui penyerapan oleh akar tanaman. Selanjutnya sistem ini dapat berpangaruh terhadap perbaikan kualitas air media pendederan ikan, khususnya kandungan ammonia $\left(\mathrm{NH}_{3}\right)$ (Nugroho et al., 2012).

\section{Kesimpulan}

Sistem akuaponik dengan tanaman berbeda memberikan pengaruh yang berbeda terhadap sintasan atau tingkat kelangsungan hidup dan pertumbuhan bobot mutlak tetapi tidak 
berpengaruh terhadap pertumbuhan panjang mutlak benih ikan lele sangkuriang.

\section{Bibliografi}

Boyd, A. C.E., Lichtkoppler F., 1991. Water quality management in pond fish culture. Auburn University, Auburn, Alabama.

Departemen Kelautan dan Perikanan, 2008. Distribusi Hara dalam Kolam Ikan yang Dirancang untuk Akuaponik Skala Komersial. Laporan Hasil Riset Balai Riset Perikanan Budidaya Air Tawar Tahun Anggaran 2008. Departemen Kelautan dan Perikanan. hlm 175-184.

Effendi, M. I., 1979. Metode Biologi Perikanan. Yayasan Dewi Sri, Bogor.

Khodijah, D., Diana, R., Pinandoyo, 2015. Performa Pertumbuhan Benih Ikan Lele Sangkuriang (Clarias gariepinus) Melalui Penambahan Enzim Papain dalam Pakan Buatan. Journal of Aquaculture Management and Technology. 4(2), 3543.

Nugroho, R.N., Pambudi, L.T., Diana, C., Alfabetian, H.C.H., 2012. Aplikasi Teknologi Aquaponic pada Budidaya Ikan Air Tawar untuk Optimalisasi Kapasitas Produksi. Jurnal Saintek Perikanan 8(1).

Rakocy J, Nelson R.L., Wilson G., 2005. Aquaponics is the Combination of Aquaculture (Fish Farming) and Hydroponic (Growing Plants without Soil). In: Question and answer by Dr. James Rakocy. Aquaponics Journal. 4 (1): 8-11.

Robinette, H.R., 1976. Effect of Sublethal Level of Ammonia on the Growth of Channel Catfish (Ictalarus punctatus R.) Frog. Fish Culture. 38 (1): 26-29.

Gomez, K.A., Gomez, A.A., 1995. Prosedur Statistik untuk Penelitian Pertanian. Universitas Indonesia. Jakarta.

Saptarini, P., 2010. Efektivitas Teknologi Aquaponik dengan Kangkung Darat (Ipomoea reptans) Terhadap Penurunan Amonia pada Pembesaran Ikan Mas. [Skripsi]. Departemen MSP FPIK IPB. Bogor. $69 \mathrm{hlm}$.

Savidov, N., 2005. Evaluation of Aquaponics Technology in Alberta, Canada. Crop Diversification Center, South Alberta, Canada.

Setijaningsih, L., 2009. Peningkatan Produktivitas Kolam Melalui Perbedaan Jarak Tanaman Akuaponik Pada Pemeliharaan Ikan Mas (Cyprinus carpio). Laporan Tahunan. Balai Perikanan Budidaya Air Tawar. Bogor.

Sunarma, A., 2004. Peningkatan Produktivitas Usaha Lele Sangkuriang. Balai Budidaya Air Tawar Sukabumi. Jawa Barat.

Standar nasional Indonesia (SNI). 2000. Produksi Benih Ikan Lele Dumbo (Clarias gariepinus) Kelas Benih Sebar. Direktorat Jenderal Perikanan Budidaya. Jakarta.

Yunus, T., Hasim, Rully, T., 2014. Padat Penebaran Berbeda terhadap Pertumbuhan Benih Ikan Lele Sangkuriang di
Balai Benih Ikan Kota Gorontalo. Jurnal IImiah Perikanan dan Kelautan 6 (1). 